\title{
Seleção de Docentes em Universidades Federais: uma análise dos regulamentos ${ }^{1}$
}

\author{
Elisabete Stradiotto Siqueira* \\ Erlaine Binotto* \\ Fabiula Meneguete Vidas da Silva*** \\ Débora Nayar Hoff $f^{* * * *}$
}

\section{Resumo}

A seleção de pessoal constitui-se em um processo complexo, na medida em que envolve critérios subjetivos, além dos objetivos presentes nos regulamentos e editais. Neste artigo, objetiva-se analisar se a metodologia do concurso público avalia o candidato naquilo que lhe é demandado no contexto do trabalho docente. É uma pesquisa documental dos regimentos que regem concursos, com uso de método qualitativo e quantitativo. As categorias de análise foram: a) composição das bancas examinadoras; b) formas de avaliação; c) critérios de pontuação dos instrumentos de avaliação. Na análise, percebe-se que os critérios de escolha dos pares que avaliarão os candidatos não estão descritos claramente nos regulamentos. A questão da competência está restrita à atuação no ensino e as dimensões pesquisa e extensão tendem a ser avaliadas de forma pontual na análise do currículo dos candidatos.

Palavras-chave: Seleção. Avaliação. Critérios. Concurso.

\section{Selection of Teachers in Federal Universities: an analysis of regulations}

\section{Abstract}

The selection of staff is a complex process involving subjective beyond objectives criteria present in regulations and proclamations. This paper aims to analyze if the methodologies of public selection to evaluate the candidate in what is demanded in the teaching work context. It's a documentary research with qualitative and

1 Esta é uma pesquisa preliminar, inserida em um projeto denominado "Seleção de docentes em universidades federais: uma análise dos processos em sua concepção e execução”, aprovado no CNPq/2009 Edital Universal.

* Dra. em Ciências Sociais, Universidade Federal Rural do Semi-Árido. E-mail: betebop@uol.com.br

** Dra. em Agronegócios, Universidade Federal de Grande Dourados (UFGD). E-mail: e-binotto@uol.com.br

*** Doutoranda em Engenharia de Produção, Universidade Federal de Santa Catarina (UFSC). E-mail: fabiulamv@yahoo.com.br

***** Dra. em Agronegócios, Universidade Federal do Pampa (UNIPAMPA). E-mail: deborahoff@unipampa.edu.br 
quantitative method analysis. The regiments of public selection professor in 14 universities, available on their Websites were used. The categories of analysis have been: (a) composition of professor that will be evaluators; b) forms of assessment; c) scoring criteria of assessment instruments. The data analysis is possible to realize that the criteria for the choices of the peers that will be evaluate applicants wasn't at regulations. The selection of professor is not guided by the strategic objectives, assuming a functionalist perspective. The competence perspective is restricted to education function. The research and extension dimensions are evaluated in curriculum analysis so timely.

Keywords: Selection. Evaluation. Criteria. Public selection.

\section{Selección de Docentes en Universidades Estatales: análisis preliminar de la concepción y ejecución Resumen}

La selección de personal constituye un proceso complejo, ya que implica criterios subjetivos, además de los objetivos presentes en reglamentos y bases. El objetivo de este artículo es analizar si la metodología del concurso público evalúa al candidato en lo que se le pide dentro del contexto laboral docente. Es una investigación documental de los reglamentos que rigen concursos, con uso de método cualitativo y cuantitativo. Las categorías de análisis fueron: a) composición de la comisión examinadora; b) formas de evaluación; c) criterios de puntuación de instrumentos de evaluación. En el análisis se observa que los criterios de elección de los pares que evaluarán a los candidatos no están descritos claramente en los reglamentos. La cuestión de la competencia está restricta a la actuación de enseñanza y las dimensiones de investigación y extensión se evalúan de forma puntual en el análisis de currículo de los candidatos.

Palabras claves: Selección. Evaluación. Criterios. Concursos.

\section{Introdução}

A seleção de pessoal constituiu-se em um processo complexo por envolver critérios subjetivos, além dos objetivos presentes em regulamentos e editais. Sua evolução acompanha as transformações da área de recursos humanos no decorrer das últimas décadas, desde a criação do departamento de pessoal (MARRAS, 2000) até a perspectiva dos recursos humanos estratégicos, alinhado às estratégias corporativas (ULRICH, 2000).

Nesse percurso de desenvolvimento da área, a seleção de pessoas partiu da noção de perfil adequado a um determinado cargo, até mais recentemente, à busca de talentos, ou seja, a busca por pessoas com habilidades cognitivas, técnicas e conceituais capazes de contribuir com a inovação organizacional. Para Michaels, Handfield e Axelrod (2002) talento é o conjunto de habilidades de uma pessoa seus dons, conhecimento, experiência, inteligência, discernimento, atitude, caráter e impulsos inatos, o que inclui sua capacidade de aprender. 
Essa nova perspectiva do processo de seleção na busca de talento com foco nas competências está relacionada com as mudanças na organização do trabalho. Essas têm sido discutidas por autores como Castells (1999), Sennet (2000), Beck (1997), Heloani (1994), Toffler (2007) e, embora não haja consenso sobre como as novas caracteristicas do trabalho afetam a subjetividade do trabalhador, todos afirmam que há uma tendência de valorizar a dimensão intelectual em detrimento da atuação física.

Tal transição imprimiu maior complexidade à área, uma vez que o perfil desejado deixa de se constituir em um modelo pré-determinado para compor-se pela identificação de potencialidades cognitivas.

A contratação de profissionais aptos para trabalhar com a inovação e a criatividade implica no ambiente de trabalho, no diálogo com a diferença, em mudança e inovação. Diante desse contexto, essas transformações provocaram mudanças de enfoque e de perspectivas na área de gestão de pessoas, particularmente no subsistema de seleção.

Nesse cenário de contratação é necessária uma relação mais direta entre aqueles que serão contratados e seus parceiros organizacionais. 0 fato dos responsáveis pelos setores requisitantes passarem a atuar de forma mais decisiva e assumirem mais responsabilidades nas escolhas, provocou maior delegação no processo. Dessa forma, a tarefa de selecionar tornou-se sistêmica, envolvendo os responsáveis: pelo processo de gestão com pessoas e pelos setores que deverão acolher o novo funcionário. Trata-se de uma responsabilidade compartilhada.

0 processo de seleção no contexto contemporâneo deveria estar orientado por uma concepção de complexidade cuja essência, para Morin (1990), é a impossibilidade de homogeneização. Dessa forma um processo de seleção não poderia se limitar a adaptação a padrões pré-determinados e sim estabelecer processos de desorganização, pela introdução do novo, buscando a construção de novas ordens.

No que se refere ao setor público essa questão torna-se ainda mais complexa. Rusaw, A. e Rusaw, M. (2008) evidenciam que a função do RH (Recursos Humanos) no setor público é crítica e visa à integração dos demais sistemas. Neste contexto, ao mesmo tempo em que o perfil do mercado de trabalho exige sistemáticas mais amplas e dinâmicas de seleção, que permitam captar as competências objetivas e subjetivas dos candidatos, a rigidez dos processos públicos, determinados por leis e decretos, tendem a provocar engessamento na sistemática de seleção. Este engessamento da conformação dos concursos limita o rol de instrumentos que se pode usar para avaliar os candidatos, impedindo, talvez, que se observem suas reais competências.

Considerando que o setor público, no Brasil, é um dos maiores agentes de contratação de pessoas, e que estas pessoas exercerão funções de interesse público, 
pode-se dizer que a forma de seleção e recrutamento público constitui-se tanto em uma questão de eficiência da gestão organizacional, quanto em uma questão social. Isso se torna ainda mais contundente quando se está trabalhando com a seleção de profissionais que irão, por um lado, formar novos profissionais, por outro, responsabilizar-se pelo avanço científico e tecnológico do país.

A seleção pública de docentes pelas universidades federais é o foco deste estudo. Tal perspectiva justifica-se pela necessidade de discussão de um processo tão complexo e pouco explorado na produção científica brasileira. Sendo a universidade um espaço de inovação e geração de conhecimento, deveria passar por suas atividades a busca por mudanças de paradigma, inclusive no que concerne às características desejadas para seus profissionais.

Diante do exposto, interessa responder à seguinte questão de pesquisa: A metodologia utilizada nos concursos públicos é capaz de selecionar docentes com perfis adequados às atividades que irão realizar na universidade? Nesse cenário, o objetivo desse artigo é analisar se a metodologia do concurso público consegue avaliar o candidato naquilo que lhe é demandado para o trabalho docente.

Para tanto, o artigo está organizado em seis seções, sendo a primeira reservada à introdução do assunto. A segunda seção apresenta os elementos teóricos que contribuem para a compreensão da temática e análise do objeto. Na terceira seção serão apresentados os procedimentos metodológicos utilizados. A quarta seção traz os resultados da pesquisa, seguida da seção de análise. A sexta seção é reservada às considerações finais seguida das referências utilizadas no estudo.

\section{Revisão teórica}

Como indicado na primeira parte desse artigo, a problemática proposta se estabelece na interface de várias dimensões, quais sejam: gestão com pessoas e tendências do processo de seleção, competência e perfil do docente no contexto contemporâneo, processo de seleção de docentes como forma de avaliação.

\section{Gestão com Pessoas e tendências do processo de seleção}

A área de RH assume papéis diferenciados desde a sua criação no contexto organizacional. Gil (2001, p.17) entende que o papel da gestão de pessoas, denominação dada no século XX, depois de ter evoluído de "administração de pessoal, relações industriais e administração de recursos humanos", tem como objetivo principal fazer com que as pessoas cooperem para que os objetivos organizacionais e individuais sejam atingidos. A utilização do termo gestão de pessoas é considerada pelo autor como algo mais amplo que administração de $\mathrm{RH}$ que colocava os recursos humanos ao lado dos demais recursos. 
Davel e Vergara (2001) salientam o importante papel que as pessoas exercem nas organizações no que se refere à inovação, criação, re-criação e sua contribuição para a vitalidade da organização. As transformações da ARH (Administração de Recursos Humanos), para esses autores, centram-se em três abordagens:
a) funcionalista;
b) estratégica; e
c) política.

$\mathrm{Na}$ funcionalista há uma sintese do desenvolvimento do campo teórico da ARH apoiado em técnicas, procedimentos e ferramentas. Na abordagem estratégica as políticas de pessoal estão integradas ao planejamento estratégico, a responsabilidade pelas pessoas passa do gerente de pessoal para o gerente de linha, o enfoque coletivista desloca-se para o individualista, os chefes e superiores são facilitadores buscando o comprometimento e a iniciativa das pessoas. A abordagem política toma como referência as "zonas de convergência entre indivíduo e organização e suas dimensões políticas, como também as divergências entre os interesses das pessoas" (DAVEL; VERGARA, 2001, p. 38). Dessa forma, o processo de seleção tem perfil diferenciado para cada uma dessas abordagens.

A seleção para Ivancevich (2008, p. 214), "é o processo por meio do qual a organização escolhe, com base em uma relação de candidatos, aquele ou aqueles que atendem melhor aos critérios de seleção para preencher as posições disponiveis, levando em conta as condições ambientais do momento". A perspectiva do processo "é atender ou superar os padrões de desempenho da organização".

Entre os meios utilizados para operacionalizar o processo estão: formulários, testes e entrevistas, sendo que essa última merece destaque. Bohlander, Snell e Sherman (2003) afirmam que a entrevista possui um papel central no processo de seleção e são raros os casos que funcionários tenham sido contratados sem passar por ela. Daft (2007, p.305) percebe a entrevista como "um canal de comunicação que permite à organização e ao candidato coletarem informações que, caso contrário, seriam dificeis de obter".

Hanashiro, Teixeira e Zaccarelli (2007) evidenciam a importância da inclusão dos aspectos culturais no processo seletivo, ou seja, é importante conhecer os valores que devem ser preservados e desejados a fim de permitir a integração do profissional contratado. Em vista disso, algumas empresas facilitam o processo seletivo ao aceitarem indicações de nomes de pessoas de suas relações, por funcionários, pela relação de confiança que se estabelece por meio da crença de que estes não fariam sugestões de nomes de candidatos que não fossem confiáveis. 
Outro aspecto apontado pelos autores, que deve ser considerado no processo seletivo, são as relações de poder existentes nas organizações e sua influência na escolha de pessoas. Salientam a importância da rede de relacionamentos, pessoas que apóiam grupos, grupos e subgrupos com idéias divergentes e suas participações no poder. Essa arena política poderá determinar a escolha de um candidato pela sua competência técnica prejudicando uma escolha estratégica, bem como quem será o responsável pela escolha da pessoa, métodos e técnicas que serão adotados no trabalho (HANASHIRO; TEIXEIRA; ZACCARELLI, 2007).

Ivancevich (2008) ao abordar os critérios de seleção de candidatos evidencia a importância de atender o objetivo principal metas do sistema de seleção: identificar com precisão os candidatos que possuem conhecimentos, habilidades e atitudes, bem como outras características exigidas pelo cargo. Ademais, o sistema de seleção deve permitir que se escolha o candidato que possua as características necessárias no momento da contratação, tenha condições de absorver as proporcionadas durante o treinamento e outras que serão desenvolvidas após a contratação. Em vista disso, a seleção deve contemplar diferentes critérios para quantificar características qualitativamente diferentes.

As decisões ou escolhas de candidatos com base na intuição podem ser, na verdade, apoiadas em "uma idéia fixa, fruto da falta de flexibilidade, ou de uma 'armadilha mental', que empobreceu o pensamento ao se tomar a decisão" (HANASHIRO; TEIXEIRA; ZACCARELLI, 2007, p. 135). Nas categorias de critérios para seleção devem estar contemplados a educação formal, a experiência e desempenho passados, características físicas, características pessoais e tipos de personalidade. No que se refere ao bom desempenho passado do candidato, especialistas entendem que este pode ser um bom indicador de desempenho satisfatório no futuro, isto quer dizer que a experiência pode indicar a existência de habilidades e atitudes em relação ao trabalho. As caracteristicas pessoais e tipos de personalidade podem dar preferência a candidatos com algumas condições relacionadas a estado civil, sexo, idade, etc. Para complementar isso, Ivancevich (2008) afirma que as características de personalidade adequadas ao cargo podem trazer resultados significativos.

Para Ivancevich (2008, p. 219) a confiabilidade e validade nos critérios de seleção ocorrem quando os resultados das decisões tomadas produzem resultados seguros, ou seja, se as técnicas adotadas possibilitam determinar qual funcionário será mais bem sucedido no cargo a ser ocupado. Porém, quando a avaliação depende do julgamento das pessoas, como exemplo a entrevista, a confiabilidade passa a ser determinada pelo grau de isenção, corretude e coerência dos avaliadores. Assim, a validade do processo está relacionada tanto ao objeto medido pelo teste, quanto à qualidade do resultado obtido. Isso requer que o avaliador conheça profundamente o objeto de sua avaliação, o que leva o processo a recorrer à avaliação por pares, uma vez que envolve pessoas e critérios subjetivos. 


\section{Competência e perfil do docente no contexto contemporâneo}

Como exposto anteriormente, a seleção de pessoas tem apresentado uma tendência de priorizar não apenas processos de adequação a um perfil pré-determinado, mas principalmente atrair pessoas que possam contribuir com o enfrentamento das incertezas organizacionais e a inovação. Assim, a análise das competências deveria constituir-se como um fator significativo, quiçá determinante da escolha.

A expressão "competência" tem sido ao mesmo tempo, um dos conceitos mais empregados e mais controvertidos no jargão da administração contemporânea. Muitos entendem estar tratando do significado de competência, mas de fato estão recorrendo a outros conceitos, como os de qualificação, atribuições, performance, sem contar os outros diferentes atributos que são tratados como competências (RUAS, 2001). Para Fleury, M. e Fleury, A. (2001) competência é uma palavra do senso comum que pode ser utilizada para designar uma pessoa com qualificação para realizar alguma coisa.

Para este trabalho, optou-se justamente pelo conceito de competência proposto por Fleury, M. e Fleury, A. (2001, p. 188), "um saber agir responsável e reconhecido, que implica mobilizar, integrar, transferir conhecimentos, recursos e habilidades, que agreguem valor econômico à organização e valor social ao indivíduo."

E como isso se aplica no caso dos docentes universitários? Vários autores como Morin (1991), Serres (1993) e Demo (2003), defendem, há quase meio século, que a formação do professor do Ensino Fundamental até a Pós-Graduação passa pela identificação da pesquisa como método de ensino.

$\mathrm{Na}$ universidade, ensino, pesquisa e extensão compõem o tripé que sustenta o fazer acadêmico. Esta triade implicou, até o momento, uma intencionalidade e não a articulação que coloque em crise a fragmentação existente entre os termos. Com isso não se estabelece o esperado processo de hibridização, no qual a interface entre os elementos é mais relevante do que a autonomia e isolamento pré-existentes. Em outros termos, para a educação, o ensino sem a pesquisa rapidamente tornase obsoleto e a extensão sem pesquisa configura-se em voluntarismo, assim como não existe pesquisa que em sua aplicação não responda, em algum momento, às demandas do ensino e da extensão.

O Plano Nacional de Educação Brasileiro (2001) afirma que:

No mundo contemporâneo, as rápidas transformações destinam às universidades o desafio de reunir em suas atividades de ensino, pesquisa e extensão, os requisitos 
de relevância, incluindo a superação das desigualdades sociais e regionais, qualidade e cooperação internacional. As universidades constituem, a partir da reflexão e da pesquisa, o principal instrumento de transmissão da experiência cultural e científica acumulada pela humanidade. Nessas instituições apropria-se o patrimônio do saber humano que deve ser aplicado ao conhecimento e desenvolvimento do País e da sociedade brasileira. A universidade é, simultaneamente, depositária e criadora de conhecimentos (BRASIL, 2001).

Vale salientar que a função da universidade é a formação e que esta implica na produção e atualização de conhecimentos, neste sentido, a pesquisa que não é traduzida para os processos de ensino e extensão tem sua função reduzida, visto que não responde a função social formadora da universidade.

0 que singulariza a universidade diante de outros centros de pesquisa é sua responsabilidade em articular o tripé ensino, pesquisa e extensão de forma complexa, ou seja, tais dimensões do fazer acadêmico devem necessariamente contribuir para com a sociedade através de processos de formação. No Brasil, esta indissociabilidade acaba sendo preceito constitucional para a organização das universidades: "Art. 207. As universidades gozam de autonomia didático-científica, administrativa e de gestão financeira e patrimonial, e obedecerão ao princípio de indissociabilidade entre ensino, pesquisa e extensão" (BRASIL, 1988).

Contudo, formação aqui não se reduz à dimensão instrumental, de acordo com Manzini-Covre (2008, p. 39):

a passagem formativa está além de ser melhor preparada no que diz respeito ao caráter cognitivo do professor, está além da questão curricular, ela depende sim do modo como se passa essa formação. A formação não é da ordem das coisas, mas da ordem simbólica, dos significados. Reiteramos também, que tem vínculo com o desejo, que é da ordem dos sentidos - para que possamos prosseguir nossa existência.

Enfrentar o problema da formação de novos profissionais competentes para as exigências da sociedade consiste na capacidade de sistematização, de inovação e aprendizagem permanentes, cujo instrumento de trabalho só pode ser a pesquisa.

Pesquisa neste sentido refere-se a uma ação conjunta entre professor e aluno, cabendo ao primeiro o papel de orientador e ao segundo o papel de autor e responsável pela elaboração do pensamento. Não faz sentido, na universidade, uma pesquisa apartada do processo de ensino. Os projetos de investigação dos docentes devem alimentar a inserção dos discentes no campo da produção do conhecimento, superando 
uma formação conteudista que cria laços de dependência desse novo profissional com instituições de pesquisa que indefinidamente serão responsáveis pela proposição de novos conhecimentos para o enfrentamento dos problemas sociais.

Portanto, pesquisa aqui tem um sentido amplo e adequado aos diferentes estágios de escolaridade. Segundo Demo (2003), ela deve abranger desde o ensino fundamental até a graduação, ou ainda na concepção de Lima (2006) a atividade docente caracteriza-se por ser uma atividade que oferece constantes riscos e desafios, já que esse profissional se depara constantemente com o inusitado e com a construção da personalidade de um ser humano.

Isto considerado, pode-se dizer que a função docente vai além daquela que é própria do pesquisador, tratam-se de atividades diferenciadas, mas não excludentes.

Fernandez (1990) propõe o conceito de ensinante e aprendente para referir-se a dimensão afetiva que envolve os processos de aprendizagem, e alerta sobre a alternância de papeis que professores e alunos devem assumir diante deste processo. Neste caso o processo de aprendizagem deve conduzir à capacidade de autoria, em última instância, autonomia do discente.

Neste sentido, a escolha pedagógica pela pesquisa deve superar o conteudismo e a fragmentação do conhecimento gerado na universidade. Implica na reorientação do papel do docente e discente, como parceiros na produção do conhecimento, ou seja, cabe ao docente o dever de orientar o método científico e ao discente a responsabilidade de produzir a pesquisa, de acordo com seu estágio de formação.

De acordo com o ForGRAD (FÓRUM DE PRÓ-REITORES DE GRADUAÇÃO DAS UNIVERSIDADES BRASILEIRAS, 2002, p. 14) "O trabalho docente deve vincular a ciência produzida historicamente com a prática social educativa, pela ênfase nos saberes, para além das competências e habilidades, desenvolvendo pesquisa como produção do conhecimento e também como postura reflexiva sobre a práxis pedagógica". Isso implicará, necessariamente, nas características desejadas para este profissional.

À luz de Pierce uma definição muito geral e sintética de pesquisa seria a seguinte: "toda investigação de qualquer espécie que seja, nasce da observação de algum fenômeno surpreendente, de alguma experiência que frustra uma expectativa ou rompe com um hábito de expectativa" (SANTAELLA, 2001, p.111).

Dessa forma, a competência do docente deve estar associada a essa complexidade de concepção do que seja o fazer universitário, não há distanciamento entre as dimensões ensino, pesquisa e extensão, mas há entre elas um diálogo dinâmico no qual os discentes estão envolvidos. 
A seleção desse profissional envolve a percepção de sua capacidade de articular a indissociabilidade prevista inclusive nos instrumentos legais da educação.

\section{Processo de seleção de docentes como forma de avaliação}

Todo processo de seleção implica um tipo de avaliação. Assim, a seleção de pessoas é uma forma de avaliação, pois atribui valores a candidatos tornando-os aptos ou não a fazer parte de uma organização. Ao mesmo tempo, trata-se de um processo que envolve a dimensão da objetividade e subjetividade do responsável pela seleção.

Segundo Gatti (2000) avaliações constituem-se em processos que produzem estímulos para mudanças e transformações e não devem ser utilizados como forma de punição e perda de valor do trabalho.

No caso da seleção de pessoas, o feedback desses processos ainda é algo a ser aprofundado, pois em muitos casos esse se encerra com decisões entre incluídos e excluídos com poucas possibilidades dos últimos dialogarem sobre sua situação.

Esse é um desafio para seleção de pessoas, visto que na grande parte dos casos os critérios de inclusão são definidos por modelos pré-concebidos e, que estejam coerentes com a cultura da organização. Isso pode deixar pouco espaço para a expressão da diferença, ou seja, a seleção corre o risco de constituir-se como reprodução do existente, deixando poucas possibilidades para a novidade.

De acordo com Demo (1996, p. 29-30), a avaliação:

É atributo humano [...], elaboração processual [...], alimentase da utopia da perfeição [...], é criatividade, inovação, intervenção alternativa [...], participação [...], não é mais tipicamente melhor [...], implica em compromisso humano com a humanização da história [...], implica a construção de instrumentos e das estratégias mais efetivas da intervenção histórica humanizadora e criativa, que é o manejo do conhecimento [...], é manifestação política [...].

Tais considerações apontam avaliação e qualidade enquanto binômios que devem se desenvolver de forma articulada, sendo que o conteúdo de ambos é fruto de um processo de construção coletiva e processual. A partir da realidade dos agentes nele integrados, o que traz para o contexto outro elemento importante e indispensável, a participação.

Espera-se, portanto, que o processo de avaliação contribua com o avaliado. Neste sentido, deve ser claro, argumentado, transparente, de forma que o avaliado tenha 
condições de se posicionar, tanto no que diz respeito a sua defesa, quanto no sentido da reconstrução de seu próprio conhecimento (DEMO, 1996; RODRIGUES, 2002).

Além disso, deve ser fruto de um trabalho coletivo tanto no que se refere a sua construção quanto no que diz respeito à operacionalização; assim a participação dos agentes envolvidos é fundamental para garantir sua qualidade. Para Demo (1996, p. 35) a participação aberta e transparente dos agentes é o único caminho no sentido de garantir a legitimidade do processo e, fazendo com que seja assumido por todos. A fim de garantir uma participação real, alguns princípios são fundamentais:

Não faz sentido um processo avaliativo que tenha como resultado típico a exclusão do avaliado [...], um processo avaliativo no qual o avaliado não tenha chance de defesa [...], não pode conviver com procedimentos sigilosos [...], a autoridade do avaliador emerge do mérito historicamente comprovado e sempre questionável [...], não se pode ocultar atrás de auto-avaliações [...], avaliação é instrumento necessário e permanente de seu processo de qualificação histórica.

Ainda considerando os aspectos metodológicos da avaliação, entende-se ser importante não limitar tal processo apenas a padrões globais de referência, mas garantir uma análise específica do desempenho individual de cada agente, no sentido de analisar em que medida suas potencialidades tem sido desenvolvidas adequadamente.

Cabe ainda enfatizar que a forma de avaliação através de bancas examinadoras se assemelha a algumas das características e dificuldades da avaliação por pares usada na construção do conhecimento acadêmico científico.

Bence e Oppenheim (2004) usam o termo peer review para designar o método de controle de qualidade que usa experts independentes para fazer a análise de artigos submetidos a eventos e periódicos e propostas de pesquisa. Para estes autores essa abordagem deveria usar experts qualificados para avaliar o trabalho de experts não tão qualificados. Grivell (2006) é enfático ao afirmar que o avaliador é aquele que separa o "joio do trigo", para que seja assegurada a qualidade da produção.

No caso dos concursos públicos para docentes, seria possível estabelecer uma analogia, ou seja, são experts que vão selecionar profissionais para desempenhar atividades acadêmicas. Assim, a consulta prévia aos pares coloca-se em um contexto de construção de consensos e verdades. No que diz respeito aos concursos públicos seria a preservação da credibilidade do corpo docente que deve alimentar a produção da ciência no contexto das universidades, mas que deve também formar a nova geração de profissionais para atuar no âmbito da própria ciência, mas também no âmbito do mercado. 
Percebe-se que a avaliação por pares, longe de se aproximar do ideal dentro do qual foi concebida, tende a estar configurada como um espaço de ratificação do pensamento estabelecido, criando, muitas vezes, limite ao crescimento da ciência. Transposto para o espaço de seleção de professores passa-se a esperar que a sistemática ratifique procedimentos historicamente estabelecidos, com pouco espaço para inovações.

Pode-se dizer que os procedimentos estabelecidos para selecionar novos professores precisam encontrar saídas, nos instrumentos de seleção estabelecidos, para superar os limites impostos pelos aspectos legais, históricos e pela avaliação por pares, para aproximarem-se das tendências recentes da ARH que permitam perceber as competências dos candidatos e selecionar aqueles que mais se aproximam das desejáveis para uma universidade que se orienta pela indissociabilidade entre ensino, pesquisa e extensão.

\section{Procedimentos metodológicos}

A pesquisa que deu origem a este artigo está organizada em duas etapas:

a) pesquisa sobre as normas dos concursos expressas nos regulamentos das universidades; e

b) entrevista com as comissões de seleção e chefes de departamento das universidades, professores que tenham participado de banca de seleção e professores que tenham participado do processo seletivo.

Este artigo discute a primeira etapa da pesquisa, sendo que a segunda está em desenvolvimento. Trata-se de um estudo documental, cujo método de análise leva em consideração aspectos qualitativos e quantitativos. Os aspectos qualitativos estão presentes no cruzamento das informações obtidas com elementos da base teórica e entre os documentos analisados. Os aspectos quantitativos são evidenciados quando se indica o montante de instituições que executam uma ou outra prática observada.

As universidades públicas federais foram escolhidas como objeto de análise em função do processo de expansão que vem passando nos últimos três anos e pela peculiaridade dos processos de seleção que precisam usar, os quais são determinados, em grande parte, por aspectos legais e estão sob observação constante da sociedade, principalmente através do Ministério Público. Também contribuiu nessa escolha o perfil dos contratados, ou seja, trabalhadores do conhecimento, o que garante complexidade ao processo de seleção. A Portaria no. 475, de 26 de agosto de 1987, estabelece:

Art. 10 - Serão estabelecidos em regulamento, pelo Conselho Superior competente da IFE, para cada carreira do Magistério: I - os critérios para concessão, fixação e alteração dos regimes de trabalhos dos docentes; 
II - os limites máximos e mínimos de carga horária de aulas, segundo os regimes de trabalho, observadas, a critério do Conselho, a natureza e diversidade de encargos do docente; III - o processo de acompanhamento e avaliação das atividades dos docentes.

$\S 1^{\circ}$ - Para o Magistério Superior, o limite mínimo a que se refere o inciso II, não poderá ser inferior a 8 (oito) horas semanais, em qualquer regime, nem o máximo poderá ser superior a $60 \%$, no regime de 20 horas, $50 \%$ nos de 40 horas e de dedicação exclusiva.

$\S 2^{\circ}$ - No caso da opção prevista no art. 32 do Anexo ao Decreto $n^{\circ}$ 94.664, de 1987, o Conselho Superior competente regulamentará os procedimentos para a concessão da gratificação, a partir dos limites mínimos não inferiores aos indicados no parágrafo único do citado artigo.

$\S 3^{\circ}$ - A carga horária didática a ser cumprida pelo docente de $1^{\circ}$ e $2^{\circ}$ graus terá como limite máximo $60 \%$ da carga horária do respectivo regime do trabalho, fazendo jus à gratificação prevista no art. 33 do Anexo ao Decreto 94.664/ de 1987, o docente que ministrar no mínimo, 10 horas/aulas semanais, em regime de 20 horas, e 20 horas/ aulas semanais, em regime de 40 horas ou de dedicação exclusiva (BRASIL, 2010).

A análise documental foi feita a partir regimentos que dirigem os concursos, que foram escolhidos porque regem os editais e constituem-se em uma orientação mais ampla sobre o processo de seleção. Os regimentos foram selecionados utilizando-se o critério da acessibilidade. Para tanto, foram consultados os sites das universidades federais. Nesse processo de busca foram encontrados 14 regulamentos, num universo de 59 universidades federais estabelecidas. Isso não significa que a inexistência de tal documento nas universidades que ficaram fora da amostra. Em alguns casos eles não estão disponiveis na internet ou, caso estejam, seu acesso não foi localizado pelos pesquisadores. Além disso, duas das universidades federais mais novas (UNILA e UNILAB) não estavam em atividade no momento da pesquisa.

Cabe ressaltar que para algumas universidades, quando o regulamento não foi encontrado no site, foram feitos contatos telefônicos buscando obter acesso. A informação recebida foi de que os editais respondiam aos requisitos do concurso e os regulamentos mesmo sendo instrumentos necessários, ainda estavam sendo construídos.

Para efeito de análise foram consideradas apenas as normas de seleção para professor adjunto. As categorias de análise foram assim constituidas: 

a) composição das bancas examinadoras;
b)formas de avaliação; e
c) critérios de pontuação dos instrumentos de avaliação.

\section{Apresentação dos resultados}

Os resultados foram organizados de acordo com as categorias de análise e serão apresentados na seguinte sequência: composição das bancas, formas de avaliação e critérios de avaliação.

\section{Composição das bancas}

Nas universidades federais pesquisadas as bancas dos concursos públicos para docentes são compostas, em sua maioria, por três docentes, sendo que, em alguns casos, há referência nos regulamentos a cinco componentes.

Os regulamentos demonstram que existe uma tendência a privilegiar a participação de membros da própria instituição, contudo, em todos há indicação da necessidade de pelo menos um dos membros ser de outra universidade.

Somente dois regulamentos pesquisados fazem menção ao perfil dos membros da bancas, no que se refere à competência, mesmo assim de forma vaga. Um dos documentos refere-se à experiência na área e outro à formação na área do concurso. Os outros regulamentos exigem somente a titulação de doutor, para o caso de bancas para professor de adjunto, e que sejam docentes do magistério superior (ativo ou aposentado).

As bancas são definidas, com maior frequência, pela unidade acadêmica que irá acolher o docente, embora em pelo menos quatro casos seja uma indicação da reitoria. Nesse caso, não está claro se a unidade indica e a reitoria apenas homologa, ou se é prerrogativa desta a indicação da banca.

Em um dos casos pesquisados, é de responsabilidade da banca definir os critérios de avaliação dos candidatos, no que se refere aos pesos das provas, contudo com parâmetros pré-definidos das médias finais e individuais. No que diz respeito à definição dos pontos do concurso, somente em uma universidade é de responsabilidade da banca. Para a maioria delas, a banca tem apenas o papel de avaliação e não de concepção de como deve ser este processo.

\section{Formas de avaliação}

Todas as universidades utilizam as provas: escrita, didática e de títulos. Algumas delas incluem defesa de memorial ou de projeto de pesquisa, contudo são casos isolados, principalmente se considerada a categoria de professor adjunto, sendo mais comum nos concursos para professores titulares. As que usam este 
instrumento defende-o como uma possibilidade de conhecer um pouco mais profundamente o candidato, visto a possibilidade de interação da banca com o candidato no momento da defesa. As provas didáticas são sempre opcionais, considerando indicação da área responsável.

De forma geral, a prova escrita tem como objetivo avaliar os conhecimentos específicos, a didática o desempenho pedagógico e a de títulos, a produção acadêmica, principalmente as atividades de pesquisa e extensão e a experiência no ensino.

\section{Critérios de avaliação}

Grande parte dos editais das universidades traz tabelas com os critérios de avaliação de cada uma das provas. No que diz respeito à prova de títulos, apenas dois regulamentos pesquisados consideram os critérios QUALIS/CAPES na pontuação do currículo.

Ainda que, para quatro universidades a ordem das provas possa ser definida pela banca, há uma tendência na sequência da realização da prova escrita, depois a didática e, finalmente a de títulos. Essa ordem é mais presente naqueles concursos em que essas provas têm caráter eliminatório, o que ocorre em sete casos analisados. Nas outras universidades, a média final é que determina a classificação dos candidatos, com uma média mínima de aprovação de sete pontos.

Em cinco universidades é utilizado o critério de peso em cada prova. 0 Quadro 1 indica como esses pesos estão distribuídos nas cinco universidades denominadas aqui de $\mathrm{A}$ a $\mathrm{E}$.

Quadro 1 - Pesos atribuídos as provas dos concursos nas cinco universidades que utilizam esse critério

\begin{tabular}{|c|c|c|c|c|}
\hline Universidades & Escrita & Didática & Títulos & Memorial \\
\hline A & 3 & 4 & 1 & 2 \\
\hline B & 4 & 2 & 2 & 2 \\
\hline C & 3 & 3 & 2 & 2 \\
\hline D & 5 & 3 & 2 & \\
\hline E & 3 & 3 & 4 & \\
\hline
\end{tabular}

Fonte: dados da pesquisa.

Percebe-se que somente em um caso a prova de títulos tem peso maior que as demais. Os pesos são mais relevantes nas provas escrita seguida da didática. $\mathrm{Na}$ maioria dos casos em que há provas eliminatórias elas constituem-se na prova escrita e didática. Há tendência, nos regulamentos, de que a prova de títulos seja apenas classificatória. 


\section{Análise dos Resultados}

Os resultados apresentados indicam que existe certo padrão no desenvolvimento do processo de seleção nas universidades pesquisadas.

No que se refere à banca examinadora, esta assume um papel decisivo no processo, pois concentra toda a responsabilidade pela avaliação. Elas são constituídas de forma mista (membros internos e pelo menos um externo à instituição). Esse fator alinha-se à tendência contemporânea de seleção que prioriza a participação direta daqueles que demandam a vaga.

Não foi possivel identificar nos regulamentos qualquer menção aos critérios qualitativos para definição dos membros da banca. 0 comum em todos os documentos é a exigência da formação acadêmica (doutorado) e experiência ou formação na área. Em nenhum momento a questão da produção acadêmica aparece como um filtro no processo de seleção da banca.

Pode-se afirmar que o processo de seleção de novos docentes caracteriza-se como uma "avaliação por pares". Como visto anteriormente (BENCE; OPPENHEIM, 2004) a avaliação por pares pressupõe que o avaliador tenha expertise na temática e, ainda que sua trajetória seja mais ampla do que de seus avaliados, no se refere à produção.

Obviamente, esse tipo de afirmação necessita de maiores confirmações que poderão vir na próxima etapa da pesquisa, quando serão entrevistados os chefes das unidades e também as comissões organizadoras. De qualquer forma a inexistência de critérios de competência nos regulamentos deixa um grau de liberdade na escolha de bancas que, não necessariamente, tenham o acúmulo necessário de conhecimentos para esta sistemática de avaliação.

Os critérios de avaliação docente, principalmente aqueles instituídos pela CAPES tem valorizado de forma incisiva a capacidade de produção do conhecimento dos docentes/pesquisadores como forma de atestar sua competência na formação de novos profissionais e nesse caso específico na seleção daqueles que farão parte de uma universidade (Portaria no 088, de 27 de setembro de 2006 - CAPES, 2009).

Outra questão a ser abordada diz respeito à situação das universidades ainda em formação que não contam, no corpo docente, com profissionais com a titulação necessária para participar das bancas. Nesse caso, a possibilidade de ter uma banca composta prioritariamente de membros externos é grande, dificultando o acompanhamento formal, por parte da unidade interessada, do perfil desejado do candidato para a realidade presente. Ainda que seja possível um diálogo com a banca é necessário demarcar que o poder de decisão é restrito. 
Outro aspecto não identificado nos documentos pesquisados são as formas de avaliação do trabalho da banca, tal atuação não é objeto de um processo formal que contribua para reconstrução do processo. Como visto, a avaliação é um processo de reconstrução que envolve avaliador e avaliado (DEMO, 1996), em uma relação de diálogo. A impossibilidade de uma avaliação do avaliador dificulta 0 aprimoramento reflexivo desse processo.

0 único mecanismo de expressão do candidato é o recurso, previsto em todos os regulamentos. Contudo, ele é considerado, por muitos, como um instrumento de diálogo limitado e em muitos casos visto de forma restritiva, uma vez que o candidato pode considerar que poderia se constituir em uma afronta à instituição dificultando processos seletivos futuros.

Ainda assim, quando se aborda a avaliação do avaliador acredita-se que essa não deva ocorrer somente no âmbito da relação avaliador e avaliado, mas também de avaliador e a instituição que abrigará o profissional selecionado.

Quanto aos mecanismos de avaliação utilizados nos processos de seleção as provas (escrita e didática) constituem-se nos principais instrumentos e também com maior peso no processo, como demonstrado no quadro 1.

Esse tipo de critério reforça a importância do papel da banca, pois cabe a ela o julgamento exclusivo do candidato. Ainda que se possa argumentar que ela é constituída de mais de um membro, como os critérios de sua escolha não são definidos formalmente, existe a possibilidade que a banca seja constituída pela linearidade teórica de uma determinada vertente. Nesse sentido, a avaliação da produção do candidato poderia sofrer restrições vinculadas não a sua competência, mas a sua opção de um determinado campo teórico. Nesse aspecto evidencia o critério de seleção baseado na intuição ou idéia fixa (HANASHIRO; TEIXEIRA; ZACCARELLI, 2007).

Essa é uma questão recorrente no debate da avaliação por pares (GATI, 2000; DEMO, 1996; DAVYT; VELHO, 2000), ou seja, os riscos da exclusão da diversidade e da aceitação de novas perspectivas em desenvolvimento, quando avaliadores não estão preparados e abertos para tal. Assim, ainda que a análise da produção acadêmica no currículo do candidato também esteja filtrada pela lógica da avaliação por pares, a diversidade desses é maior, e nesse aspecto, com maiores possibilidades de acolhimento da diversidade.

De forma geral os regulamentos definem os seguintes objetivos das provas:

a) escrita - avaliação do conhecimento do candidato;

b) didática - avaliação do desempenho pedagógico; e

c) títulos - avaliação das atividades no ensino superior e produção acadêmica. 
A prova escrita avalia conhecimento, capacidade de sistematização e talvez a sorte do candidato, pois na maioria dos casos são indicados entre 10 a 20 pontos e, desses, sorteados entre um a três. Pode-se afirmar que o sorteio de um ponto que o candidato tenha maior afinidade contribui muito para um resultado melhor ou uma avaliação positiva. Além disso, outro fator de sorte seria a afinidade teórica do candidato com a banca, principalmente nas áreas humanas e sociais. Dessa forma, questiona-se em que medida a prova escrita é capaz de avaliar o conhecimento do candidato ou apenas faz uma análise pontual e restritiva.

Como em muitos casos essa é a prova de maior peso e também de caráter eliminatório, a banca não terá outra possibilidade de contato com o candidato, muitas vezes excluindo-o do processo sem nenhum contato através de uma análise mais ampla de sua competência.

A prova didática avalia novamente o conhecimento do candidato, pois, na maioria dos critérios presentes nos regulamentos, um dos pontos de avaliação é o conhecimento do tema, e também sua competência pedagógica. Sobre esse último aspecto valem algumas reflexões: A prova didática não parece se constituir em uma simulação de uma aula, pois, é muito comum estar ausente desse espaço um ator fundamental, o aluno, embora as bancas sejam públicas. 0 candidato ao preparar uma aula corre o risco de ser considerado muito superficial em sua abordagem, no caso de ter tomado como pressuposto o conhecimento de um aluno de graduação de um determinado semestre absolutamente fictício, ou seja, não há parâmetros claros que definam para quem está direcionada a aula. E por outro lado, não se pressupõe que o candidato estará exposto ao processo de interação que é comum em uma aula, portanto, nessa oportunidade se avalia apenas uma dimensão do processo pedagógico com o nível de conhecimento dos pares.

Essa também é uma etapa eliminatória e em alguns casos o candidato poderá ser eliminado, como prevê alguns regulamentos, sem que a banca tenha tido acesso ao seu currículo.

Nos regulamentos das universidades, na avaliação do currículo é valorizada a experiência no ensino superior, a produção bibliográfica e técnica, e também orientações. Como foi exposto no quadro 1, o peso dessa avaliação, frequentemente é menor, e ainda, está subdivido em diversos fatores o que diminui ainda mais 0 impacto da produção bibliográfica na avaliação geral do candidato.

Na maioria dos regulamentos essa é uma prova classificatória, então é possível inferir que um candidato que tenha tido um bom desempenho nas outras provas possa ter um currículo inexpressivo e ainda assim ser aprovado, ou seja, um docente em tempo integral ministrará no máximo 20 horas/aulas e o restante de sua carga horária será destinada a pesquisa, extensão e atividades administrativas, quando for o caso. Como Demo (2003), Serres (1993) e Morin (1991) observam, a pesquisa é uma dimensão importante do fazer docente e as análises demonstraram que os concursos avaliam essa competência de forma muito superficial. 
Isso talvez se justifique pelo fato das instituições precisarem, em primeira instância, de professores para atuação em sala de aula, prioritariamente com a graduação. As atividades de pesquisa, apesar de importantes pela vinculação do profissional à construção do conhecimento, tem se mostrado como elementos determinantes de escolha de profissionais para atuação na pós-graduação, depois que já compõem o quadro das universidades.

Ainda que se considere que o título de doutor, de alguma forma indica essa competência, o curriculo demonstra como, depois da obtenção desse grau de formação, o docente deu continuidade a essa dimensão do seu fazer acadêmico. Neste sentido, tal título expressa apenas uma face da interação deste profissional com este processo.

Dessa forma, a análise dos instrumentos de avaliação utilizados na seleção de docentes pode revelar um julgamento fragmentado e pontual do candidato e ainda entrecortado pelo julgamento objetivo e subjetivo da banca, principalmente no que diz respeito a opções teóricas demarcadas no critério de sua escolha.

Vale salientar que em algumas universidades o critério de avaliação dessas etapas não é eliminatório, sendo selecionado aquele que obtiver, no mínimo, média geral sete. Nesse caso, a fragmentação das competências do candidato é minimizada, mas a limitação da capacidade de avaliação de cada etapa se mantém.

A defesa de projeto de pesquisa ou de memorial é um instrumento de avaliação pouco utilizado. Contudo, constitui-se em um momento em que equívocos ou avaliações direcionadas nas etapas anteriores poderiam ser minimizados, visto que é a única possibilidade de diálogo entre avaliador e avaliado, ou seja, se constituiria no espaço para a entrevista. Retomada a literatura sobre processo seletivo nas organizações, a entrevista tem se mostrado o instrumento mais eficaz e que gera melhores resultados (LIMONGI FRANÇA, 2007).

Os editais acabam por refletir a prática compartimentalizada do fazer docente, criticada quando se busca o ideal da universidade. Em nenhum documento analisado percebe-se uma busca por construir espaço ou instrumento avaliativo que permita perceber a capacidade do candidato em trabalhar com a indissociabilidade entre ensino, pesquisa e extensão. Talvez o instrumento mais próximo desta idéia seja a defesa do memorial, onde o candidato tem a chance de relacionar seu fazer docente com objetivos futuros de atuação. Mesmo assim, não é algo que esteja explícito no processo, o que ratifica os limites históricos deste fazer.

\section{Considerações finais}

0 objetivo desse artigo foi analisar se a estrutura do concurso público avalia o candidato naquilo que the é demandado no contexto do trabalho docente. Considerando que o professor universitário possui atribuições orientadas pela indissociabilidade 
entre ensino, pesquisa e extensão, é possivel constatar que a seleção de docentes nas universidades federais é um processo que carece de revisão e aprimoramento para que contemplem os objetivos estratégicos das instituições, conforme evidenciado por Jones e George (2008) e Dutra (2002) e contemplem uma abordagem mais ampla do conceito de docência, ou seja, seu papel de ensinante (FERNANDEZ, 1990).

Outro aspecto a ser considerado é que a estabilidade presente na esfera pública dá ao candidato secionado a oportunidade de permanecer nela pelo menos 30 anos, considerando a nova lei de aposentadoria para homens e mulheres (idade, tempo no cargo e contribuição). Os processos que acarretam demissão não se mostram tão comuns quando os profissionais não atendem aos perfis de competências necessárias a essas organizações. Nesse sentido, equívocos cometidos durante a seleção encontram pouca possibilidade de correção ao longo do tempo e quando encontram esta possibilidade, provocam desgastes para a instituição.

Como a universidade se caracteriza pela diversidade de conhecimentos e do diálogo, não fica perceptível nos processos o espaço para tal, uma vez que a escolha dos pares que avaliarão os candidatos, não apresenta requisitos tão claros nos regulamentos.

No que diz respeito à gestão de pessoas nessas instituições, os regulamentos não deixam claro seu papel, dando a entender que possuem uma abordagem muito mais funcionalista que estratégica (DAVEL; VERGARA, 2001). Na abordagem estratégica seria considerada a construção e gerenciamento do capital intelectual, alinhada à estratégia da instituição que se refere ao desenvolvimento do ensino, pesquisa e extensão. De uma forma geral os regulamentos não orientam os candidatos a consultarem documentos institucionais que revelem sua dimensão estratégica, levando a crer que essa questão não é avaliada.

Ainda no que diz respeito a essa dimensão não é perceptível como a instituição espera utilizar as competências dos novos docentes para a criação de novos cursos, tanto na graduação como na pós-graduação, ampliação dos cursos de extensão e o desenvolvimento de pesquisa que gerem desenvolvimento para as regiões. Há que se considerar que uma das limitações na escolha de membros externos para compor as bancas se deve à disponibilidade de tempo dos mesmos e os recursos financeiros oferecidos para sua participação, uma vez que em alguns casos as diárias não cobrem as despesas decorrentes da participação.

Como contribuição no aperfeiçoamento do processo de seleção vale indicar:

- seleção de bancas de acordo com produção científica e experiência profissional e também critérios que possam permitir a diversidade conceitual (BENCE; OPPENHEIM, 2004) ;

- inclusão de entrevista no processo seletivo - junto ao processo de apresentação do memorial ou do projeto ou uma etapa especifica (BOHLANDER; SNELL; SHERMAN, 2003); 
- acesso aos currículos dos avaliadores antes do início do concurso;

- divulgação dos componentes da banca aos candidatos com antecedência a fim de permitir a transparência do processo de avaliação (DEMO, 1996);

- estabelecer um processo de avaliação dos avaliadores a fim de melhorar as deficiências do processo, visto que a efetividade de seus critérios de seleção em nenhum momento são objeto de análise, o que permite, em alguns casos, que um processo inadequado possa se perpetuar (RODRIGUES, 2002; CHUBIN, 1990 apud DAVYT; VELHO, 2000);

- evitar avaliações fragmentadas do candidato com etapas eliminatórias que não permitem uma análise mais ampla de suas competências (FLEURY; FLEURY, 2001);

- repensar o peso e a forma de avaliação considerando o que se espera de um docente no contexto contemporâneo (DEMO, 2003; SERRES, 1993; MORIN, 1991, FERNANDEZ, 2002).

Cabe salientar que durante a pesquisa percebeu-se a presença de alguns desses aspectos, esporadicamente, nos processos seletivos das universidades federais.

Mesmo trabalhando-se com parte dos resultados, uma vez que a pesquisa documental aqui apresentada será complementada com uma pesquisa de campo, é possível afirmar que os limites estabelecidos ao processo, seja pelos aspectos legais, seja pelas práticas históricas e pela avaliação por pares implicam na observação fragmentada do candidato, com ênfase para elementos que pretendem avaliar o conhecimento do candidato e sua capacidade de ensinar. Mesmo nestes aspectos, os processos se mostram envoltos em fragilidades que podem comprometer seus resultados.

\section{Referências}

BECK, U. Capitalismo sem trabalho. Ensaios FEE, Porto Alegre, v. 18, n. 1, 1997, p. 41-56.

BENCE, V.; OPPENHEIM, C. The influence of peer review on the research assessment exercise. Journal of Information Science. v. 30, n. 4, 2004. p. 347-368.

BOHLANDER, G.; SNELL, S.; SHERMAN, A. Administração de recursos humanos. São Paulo: Pioneira Thomson Learning, 2003.

BRASIL. Constituição da República Federativa do Brasil de 1988. Diário Oficial da União, Brasília, out. 1988.

Lei no 10.172, de 9 de Janeiro de 2001. Aprova o Plano Nacional de Educação e dá outras providências. Diário Oficial da União, Brasília, DF, n.7, p.1, 10 jan. 2001. Seção 1. 
CASTELLS, M. A sociedade em rede. São Paulo: Paz e Terra, 1999.

DAFT, R. L. Administração. São Paulo: Thomson Learning, 2007.

DAVEL, E.; VERGARA, S. C. Gestão com pessoas, subjetividade e objetividade nas organizações. In: Gestão com pessoas e subjetividade. São Paulo:

Atlas, p. 31-56, 2001.

DAVYT, A; VELHO, L. A avaliação da ciência e a revisão por pares: passado e presente: como será o futuro. História, Ciências e Saúde - Manguinhos, v. 7, n. 1, Rio de Janeiro, mar./jun. 2000.

DEMO, P. Avaliação sob o olhar propedêutico. São Paulo: Papirus, 1996. . Educar pela pesquisa. Campinas: Autores Associados, 2003.

DUTRA, J. S. Gestão de pessoas: modelo, processos, tendências e perspectivas. São Paulo: Atlas, 2002.

FERNANDEZ, A. A inteligência aprisionada: abordagem psicodedagógica da criança e sua família. Porto Alegre: Artes Médicas, 1990.

FLEURY, M. T. L.; FLEURY, A. Construindo o conceito de competências. RAC, Rio de Janeiro, Edição Especial, p. 183-196, 2001.

FÓRUM DE PRÓ-REITORES DE GRADUAÇÃO DAS UNIVERSIDADES BRASILEIRAS. Diretrizes para a formação de professores: concepções e implementação. João Pessoa: ForGRAD, 2002.

GATTI, B. A. Avaliação institucional e acompanhamento de instituições de ensino superior. São Paulo: Fundação Carlos Chagas, 2000.

GIL, A. C. Gestão de pessoas: enfoque nos papéis profissionais. São Paulo: Atlas, 2001.

GRIVELL, L. Through a glass darkly. EMBO reports, v. 7, n. 6, p. 566-570, 2006.

HANASHIRO, D.; TEIXEIRA, M.; ZACCARELLI, L. Gestão do fator humano: uma visão baseada nos stakeholders. São Paulo: Saraiva, 2007.

HELOANI, J. R. Organização do trabalho e administração: uma visão multidisciplinar. São Paulo. Cortez, 1994. 
IVANCEVICH, J. M. Gestão de recursos humanos. São Paulo: Mc Graw-Hill, 2008. JONES, G.; GEORGE, J. Administração contemporânea. São Paulo: McGraw-Hill, 2008.

LIMA, P. A. A formação de professores e pesquisadores para a educação inclusiva. São Paulo: Avercamp, 2006.

LIMONGI-FRANÇA, A. C. Práticas de recursos humanos - PRH. São Paulo: Atlas, 2007.

MANZINI-COVRE, M.L. Professores universitários - acenos reflexivos para um ensino formando professores "responsáveis". In: MANZINI-COVRE, M.L (org). Formação do professor, formação do aluno. São Paulo: Expressão e Arte Editora, 2007.

MARRAS, J. P. Administração de recursos humanos: do operacional ao estratégico. São Paulo: Futura, 2000.

MICHAELS, E.; HANDFIELD-JONES, H.; AXELROD, B. A guerra pelo talento: o talento como diferencial estratégico entre as empresa. Rio de Janeiro: Campus, 2002.

MORIN, E. Introdução ao pensamento complexo. Lisboa: Inst. Piaget, 1990.

. 0 método IV - as idéias: a sua natureza, vida, habitat e organização.

Portugal: Europa-América, 1991.

MINISTÉRIO DO PLANEJAMENTO. Decreto no 94.664, de 23 de julho de 1987. Disponivel em:<https://conlegis.planejamento.gov.br/conlegis/legislacao/ atoNormativoDetalhesPub.htm?id=2885> . Acesso em: maio 2009.

Portaria no 475, de 26 de Agosto de 1987. Disponível em:<https:// conlegis.planejamento.gov.br/conlegis/legislacao/atoNormativoDetalhesPub. htm?id=2919 . Acesso em: maio 2009.

RODRIGUES, M. E. F. Resgatando espaços e construindo ideias: ForGRAD 1997 a 2002. Niterói: EdUFF, 2002.

RUAS, R. Mestrado executivo, formação gerencial e a noção de competências: provocações e desafios. In: ENANPAD, 2001, Campinas, SP. Anais... Rio de Janeiro: ENANPAD, 2001.

RUSAW, A. C.; RUSAW, M. F. The Role of HRD in Integrated Crisis Management: a public sector approach. Developing Human Resources, v. 10, n. 3, p. 380-396, June, 2008. 
748 Elisabete Stradiotto Siqueira, Erlaine Binotto,Fabiula Meneguete Vidas da Silva e Débora Nayar Hoff

SANTAELLA, L. Comunicação e pesquisa. São Paulo: Hacker Editores, 2001.

SENNET, R. A corrosão do caráter: consequências pessoais do trabalho no novo. Rio de Janeiro: Record, 2000.

SERRES, M. Filosofia mestiça: le tiers instruit. Rio de Janeiro: Nova Fronteira, 1993.

TOFFLER, A. A riqueza revolucionária. São Paulo: Futura, 2007.

ULRICH, D. (Org.). Recursos humanos estratégicos: novas perspectivas para os profissionais de RH. 3.ed. São Paulo: Futura, 2000.

Recebido em: 17/01/13

Aceito para publicação em: 09/08/2012 